Artigo recebido em 05/03/2014

Aprovado em $15 / 05 / 2014$

PAULO BERNARDO

VAZ

UFMG - paulobvaz@ ufmg.br

Professor visitante do Programa de

Pós Graduação em Jornalismo da UFSC, colaborador do

Programa de PósGraduação em Comunicação Social da UFMG, pesquisador do

GrisPress no GRISGrupo de Pesquisa em Imagem e Sociabilidade.

ANDRÉ MINTZ

UFMG - andregmintz@ ufmg.br

Mestrando do PPGCOM/UFMG, bacharel em Comunicação Social pela mesma instituição.

\title{
Piauí, em busca do leitor perdido
}

\section{Paulo Bernardo Vaz e André Mintz}

\section{Resumo}

Compreendendo o sujeito-leitor contemporâneo como aquele que transita em um denso ambiente tipográfico no qual se multiplicam textos e práticas de leituras diversas, este artigo indaga sobre a forma de convivência e a natureza de práticas revivescentes instauradas pela revista Piauí ao deslocar fronteiras da leitura. Centrando na interação sensível entre o leitor e a publicação, propõe-se a investigar a maneira pela qual a revista se articula graficamente na proposição de uma experiência de leitura diferenciada, desbravando novos territórios do meio impresso.

Palavras-chave

Leitura, produção editorial, tipografia, experiência.

\begin{abstract}
By understanding the contemporary reader-subject as that who travels in a dense typographic environment, which presents a growing diversity of texts and reading practices, this paper inquires about the co-inhabitance and the nature of revivaling practices introduced by Piauí magazine as it shifts reading boundaries. Focusing on the sensitive interaction between reader and publication, it is proposed to investigate the way in which the magazine graphically articulates a proposition of a different reading experience, breaking new territories of print.
\end{abstract}

Keywords

Reading, editorial production, typography, experience

Estudos em Jornalismo e Mídia Vol. $11 \mathrm{~N}^{\circ} 1$

Janeiro a Junho de 2014 ISSNe 1984-6924 


\section{Cartografia das paisagens}

Em carta publicada na revista Piauí1, a leitora Gica Trierweiler relata sua descoberta da publicação: "Larguei a minha tese de conclusão de curso (bagaço de uma graduação) para entregar-me às safadezas da Piauí. Degustada com o prazer de um pré-adolescente que descobre uma revista pornográfica de quinta categoria, deliciei-me"2. Prazer explícito de uma íntima relação de leitura desfrutada por esta e outros leitores da revista, fruto de um corpo a corpo da experiência de uma publicação que se oferece sensualmente ao olhar e ao manuseio de seus leitores. Piauí, assim, instigante, surgiu em nossas discussões.

Com lançamento comercial no mês de outubro de 2006, Piauí é uma revista mensal de grande formato que remete ao jornal tablóide ( $35 \times 26 \mathrm{~cm}$ ), impressa em papel pólen soft. Configurada de um modo elegantemente tradicional, com um grid de quatro colunas (ora ocupadas separadamente, ora compondo o texto em uma única larga coluna correspondente à largura de duas estreitas), recorre a poucas fontes tipográficas, modernamente elegantes, e oferece ótima legibilidade no layout de todas suas páginas (Fig. 3 e Fig. 4). Numa rápida "folheada", não

1-Embora o nome da revista venha comumente grafado em minúsculas (piauí), por uma opção da identidade visual da publicação, optamos pela inicial maiúscula neste artigo para não tornar necessário o constante uso de aspas ou qualquer forma de grifo.

2- Piauí, ano 1,

número 7, abr 2007. p. 65 pequenos anúncios localizados na extensão da coluna externa do grid em uma ou duas páginas, como parte das inserções publicitárias, encontradas em todas as edições. Trata-se de uma revista cujos destaques textuais e imagéticos conduzem a uma experiência de leitura distinta devido à participação ativa e cuidadosa do designer gráfico, interlocutor ausente mais presente do que nunca em todas as suas páginas.

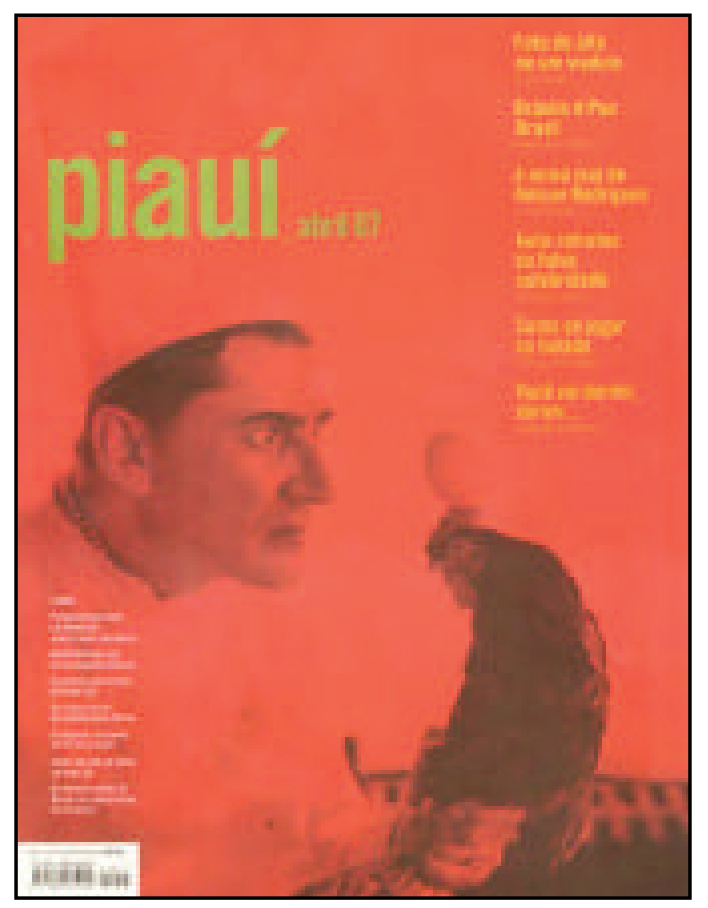

Fig. 1 - Piauí, ano 1, número 7, abr 2007. Capa.

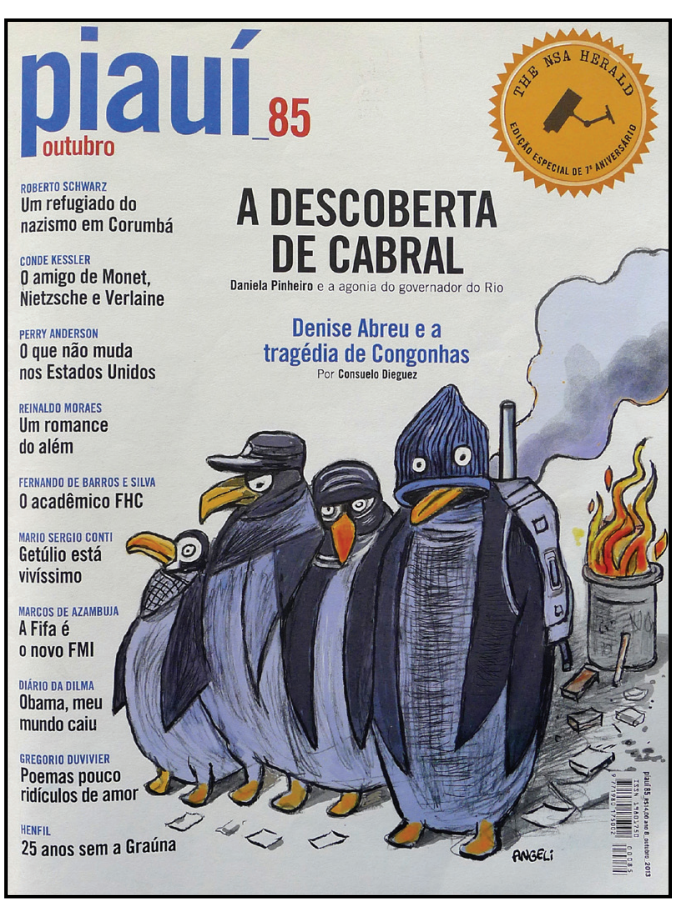

Fig. 2 - Piauí, ano 8, número 85, out 2013. Capa. 


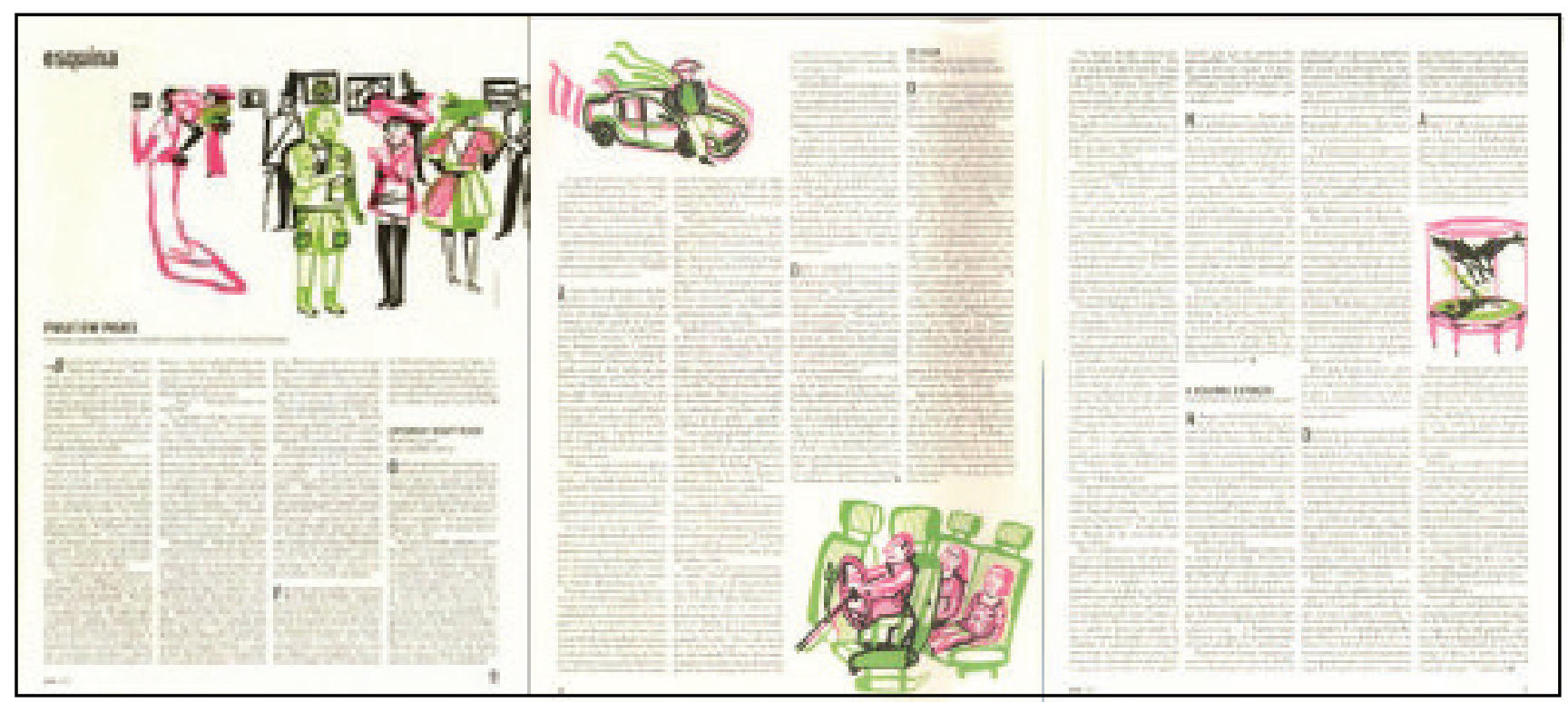

Fig. 3- Piauí, ano 1, número 7, abr 2007. p. 9-11. Seção "Esquina".

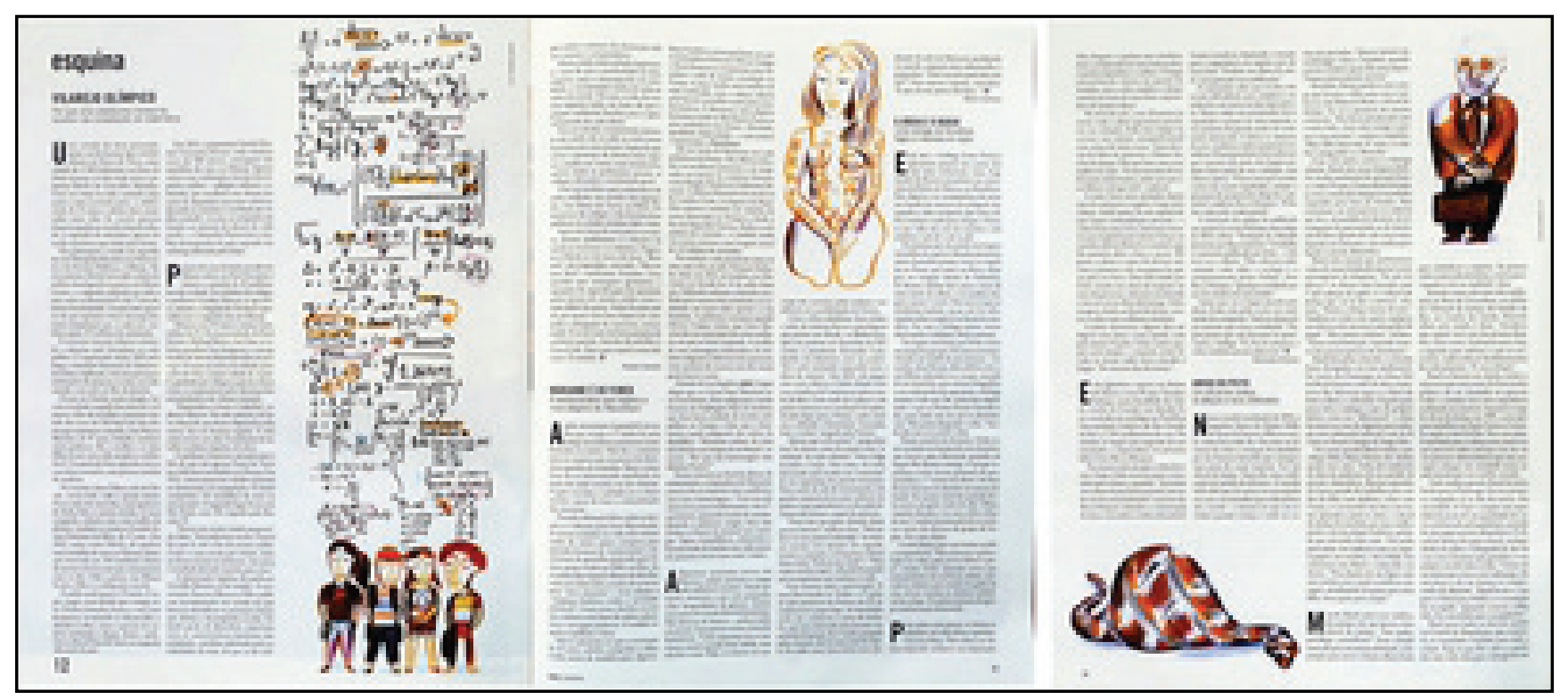

Fig. 4 - Piauí, ano 8, número 85, out 2013. p. 12-14. Seção "Esquina”.

Do ponto de vista editorial, as edições de abril de 2007 e de outubro de $2013^{3}$ demonstram como Piauí propõe ampla variedade temática e de percursos de sentido, que vai desde jocosas capas (Fig. 1 e Fig. 2) até textos ensaísticos tais como o que escreve Roberto Schwarz acerca de Anatol Rosenfeld ${ }^{4}$ e à séria homenagem à recém-falecida Rufina Amaya ${ }^{5}$, sobrevivente de chacina perpetrada por soldados norte-americanos na aldeia salvadorenha de El Mozote, na década de 1980.

Nota-se que as "chamadas de capa" mais apelam para o humor do que informam sobre o conteúdo da revista. Ao traçar tão variado leque temático, seus editores parecem visar a conquistar um público disposto a se aprazer com a variação temática proposta, com o tratamento dado à escrita e com a materialidade visual e sensível da publicação.

Com efeito, o grande diferencial da revista está no requinte literário das matérias e na beleza, conforto e discrição de sua visualidade.

Constitui-se, assim, um novo segmento de público, até setembro de 2006 não contemplado pela grande segmentação temática observada no marketing
3- Piauí, ano 1, número 7, abr 2007; Piauí, ano 8, número 85, out 2013;

4- Piauí, ano 8, número 85 , out 2013, p. 90-93;

5- Piauí, ano 1, número 7, abr 2007, p. 66. 
editorial das publicações brasileiras.

Publicação periódica sem congênere no Brasil, Piauí guarda, contudo, algumas semelhanças com outras publicações, como, por exemplo, a revista norteamericana The New Yorker (Fig. 5 e Fig. 6).

Revista semanal, circulante há 81 anos, em formato $20 \times 27 \mathrm{~cm}$, The New Yorker tem reconhecida dedicação ao jornalismo literário e ênfase na temática cultural, com a publicação de resenhas e da agenda cultural nova-iorquina. Guardadas as devidas proporções, observamos, na edição de 2 de abril de 2007 de The New Yorker ${ }^{6}$, características similares à Piauí tanto no projeto editorial quanto no projeto gráfico, como: rico tratamento da narrativa jornalística empregada; projeto gráfico discreto, com grid simples e austeridade tipográfica; ênfase no conteúdo textual; uso criterioso de estímulos visuais; e perfil editorial variado, apesar da referida e reconhecida ênfase no jornalismo cultural.

Nela se afigura, também, o espaço reservado aos pequenos anúncios e à inserção de charges e poemas ao longo da revista.

Eis que a publicação natural da maior metrópole cosmopolita do mundo visita um dos estados menos conhecidos dos brasileiros.

Nenhum demérito para Piauí por aparentar-se àquela prestimosa publicação norte-americana, pois além de dar um grande salto qualitativo em seu projeto gráfico, atualiza o diálogo ções de número de edição.

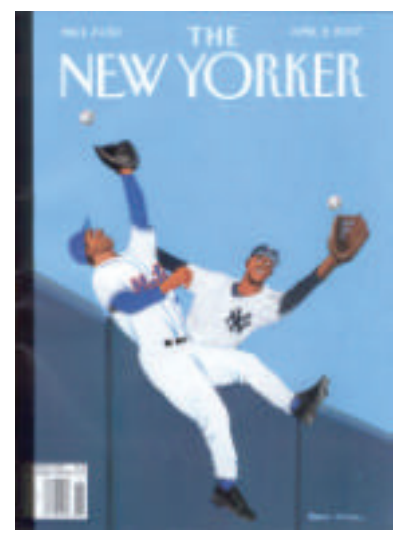

Fig. 5 - The New Yorker, 2 abr 2007. Capa.

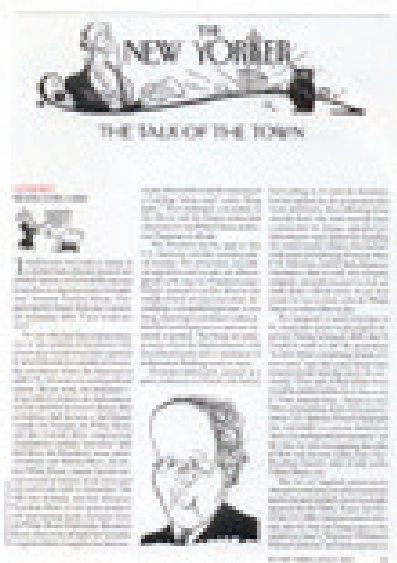

Fig. 6 - The New Yorker, 2 abr 2007. p. 25; 28-29. Seção

"The talk of the town".
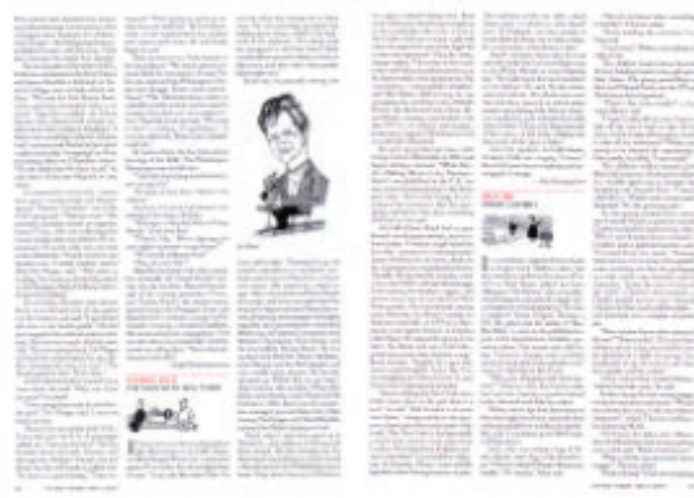

Publicação impressa nascida num tempo em que seus leitores são tanto habitués da Internet e dos dispositivos eletrônicos móveis quanto do mais remoto impresso, Piauí encontra-se no entrecruzamento de leituras diversas e atesta uma fase distinta do sujeito-leitor e dos textos a que se dedica. Cruzamento que se performa em suas páginas numa outra relação com o sujeito que a vê despontar na avalanche de publicações expostas na banca de revistas. "Deixa ver", terá ele dito em sua primeira abordagem, a buscar com as mãos aquilo que seu olhar 
alcançara nas prateleiras. Provavelmente este leitor sentisse-se como se entrasse em uma clareira silenciosa na densa selva dos impressos.

Neste sentido, a revista Piauí, que já se oferecia de início como importante fenômeno do mercado editorial brasileiro, segue ainda hoje, sete anos depois, marcando sua relevância e suscitandonos uma grande variedade de questões pela distinção de seu projeto gráfico e editorial frente ao ambiente periodístico e tipográfico circundante. Chama a atenção exatamente por sua discrição, propondo uma experiência de leitura diferenciada. Em meio a uma profusão de leituras velozes, difusas e descartáveis, Piauí parece propor uma experiência silenciosa da duração.

Noesforçode compreenderaarticulação gráfica da revista na constituição desta experiência, nos voltamos para uma reflexão sobre as práticas de leitura empreendidas pelos sujeitos na relação com os textos. Tentamos buscar subsídios à caracterização dessas práticas, bem como compreender a deriva constante efetuada pelos leitores entre práticas de leitura distintas. Voltamo-nos em seguida para os dispositivos tipográficos de modo a transpor à corporeidade da publicação os aspectos constituintes da experiência de leitura, para assim operacionalizar nossa análise da revista Piauí.

Nosso corpus, com toda a coleção de Piauí à mão, restringiu-se a duas edições da revista: ano 1 , número 7 , abril de 2007 e ano 8, número 85, outubro de 2013. A partir da observação da publicação como um todo, nossa análise empírica se detém sobre a capa e algumas páginas que destacamos conforme sua representatividade ao enfoque de nossa abordagem, suficientes para estas reflexões que apontam para muitas outras a serem perseguidas. Nos debruçamos sobre os diversos aspectos de constituição de sua materialidade - formato, papel, tinta, grid, layout, mancha, tipografia e elementos gráficos - buscando relacionálos com a experiência de leitura a partir de jogos com elementos como a temporalidade, a atenção, a estimulação, a memória e a mobilidade do corpo e do olhar.

Por fim, buscamos projetar estas observações na delimitação de um "território de leitura" da revista Piauí, tendo em vista sua inserção no universo de leitura da contemporaneidade, situando a publicação e seu leitor no entremeio de fronteiras comuns.

\section{Leituras e multiplicidade do sujeito-leitor}

$\mathrm{O}$ escrito, em suas diversas conformações tipográficas e suportes, e com seus diversos complementos, habita de forma quase onipresente a vida cotidiana, transformando nosso habitar o mundo numa incessante chamada à leitura. Este ambiente, o environnement tipográfico com que Massin abre seu $\mathrm{La}$ lettre et l'image, constitui, hoje, a efetivação da imagem de Walter Benjamin:

A escrita, que tinha encontrado asilo no livro impresso, para onde carreara seu destino autônomo, viu-se inexoravelmente lançada à rua, arrastada pelos reclames, submetida à brutal heteronomia do caos econômico. [...] E antes que um contemporâneo chegue a abrir um livro, terá desabado sobre os seus olhos um turbilhão tão denso de letras móveis, coloridas, litigantes, 
que as chances de seu adentramento no arcaico estilo do livro já estarão reduzidas a um mínimo. Nuvens de letras-gafanhotos, que já hoje obscurecem o sol do suposto espírito aos habitantes das metrópoles, tornar-se-ão cada vez mais espessas, com a sucessão dos anos ${ }^{7}$.

Esse ambiente, pois, que desde a modernidade configura uma dinâmica na qual o hiperestímulo ${ }^{8}$ obriga o sujeito a operar uma atenção transitória e difusa, capaz de alternar entre diferentes focos na restauração de uma ordem própria em meio à caótica profusão estimulante ${ }^{9}$, talvez, hoje, traga a espessura acumulada dos anos, conforme previu Benjamin, com a entrada dos novos suportes da televisão e da Internet. Ao leitor, frente a tal panorama, reivindica-se, portanto, a capacidade de efetuar o duplo movimento de localização desses textos numa realidade mais ampla e de localização de si próprio em relação a eles, adotando diferentes posições e dinâmicas de leitura necessárias à sua efetuação.

Com respeito a esta efetuação da leitura, Michel de Certeau identifica duas espécies de expectativa que orientam a relação do leitor com o texto: uma que se volta à sua literalidade e outra que "organiza uma démarche necessária para a efetuação da obra" ${ }^{10}$. Por tal distinção, propõe-se a compreender a prática de leitura para além da decodificação e da

7- BENJAMIN, [1926] 2006.

8- Conforme traba-

lhado por SINGER,

2004.

9- CRARY, 2004,

p 73.

10- CERTEAU,

1994, p. 266.

11- OLIVEIRA,

2006, p. 169.

13-Idem, p. 166.

13- SANTAELLA,

2004. o hábito de leitura, compreendido, a partir de Eric Landowski, enquanto ação volitiva de um sujeito-leitor que visa à experiência sensível daquela publicação; que busca, na repetição do ato, sentir novamente o sentido daquela ação ${ }^{12}$. Assim, compreende-se a importância da experiência sensível da leitura ao processo de construção de sentido sobre o ato de ler e à fidelização do público leitor de determinada publicação.

Tendo em vista a multiplicidade das démarches de leitura, para além desta experiência entre sujeito e texto, torna-se necessário compreender sua inserção no contexto mais amplo das diversas leituras pelas quais transitam os sujeitos no decurso de seu cotidiano. Historicamente, lidamos com um sujeito que já na modernidade deixara as bibliotecas e o isolamento de uma leitura contemplativa, se lançando no fluxo sempre movente da cidade e que, hoje, é convidado pelas novas mídias a mergulhar.

Nesta trajetória do leitor, recorremos à tipologia proposta por Lúcia Santaella ${ }^{13}$, quecompreendetrêscategoriasperceptivocognitivas de leitores: o contemplativo, meditativo; o movente, fragmentário; e o imersivo, virtual. Pretendemos, através delas, construir subsídios para se pensar a fugacidade das operações de leitura dos leitores contemporâneos pelo convívio simultâneo destes tipos, apesar da seqüencialidade histórica de seu surgimento. Logo, a retomada desta tipologia mobiliza a compreensão do atravessamento das práticas de leitura por aspectos perceptivo-cognitivos que as constituem, nos servindo à investigação sobre a maneira pela qual as publicações reivindicam estas habilidades - como 
organizam a démarche de sua própria efetuação - situando um lugar do leitor e situando a si próprias em meio ao pulular dos textos e à multiplicidade de leituras que fazem seus leitores.

Santaella aponta para o caráter cumulativo das práticas distintas de leitura, mas segue por afirmar a irredutibilidade de tais categorias na medida em que reivindicam habilidades perceptivas, sensório-motoras e cognitivas distintas ${ }^{14}$. A indagação que se coloca, contudo, é da natureza da convivência destes diversos leitores, pois, se se compreende a convivência contemporânea deles, não se pode fazê-lo senão no trânsito de um mesmo sujeitoleitor que assume estas distintas posturas, tendo em vista a já referida pluralidade do ambiente tipográfico que o circunda. Mas tal processo parece não possuir limites tão precisos. $\mathrm{Na}$ medida em que compreendemos esses sujeitos-leitores múltiplos, torna-se complicado afirmar tal irredutibilidade, uma vez que mesmo o leitor contemplativo não consegue refugiar-se dos reclames a sua atenção. Longe de uma localização precisa - seja a do recolhimento monástico, do ambiente urbano ou do espaço virtual da web - o sujeito-leitor contemporâneo transita por diversos ambientes, insinuando diferentes habilidades e práticas de leitura. Noutras palavras, reivindicase a possibilidade de adoção de leituras contemplativas transitórias, por exemplo, por sua inserção em práticas tipicamente moventes ou imersivas. Afinal, o sujeito-leitor é sempre o mesmo nesta multiplicidade, de modo que cada tipo de leitor se oferece como estágio provisório num fluxo constante de leituras.
Assim, na medida em que compreendemos a experiência de leitura de uma publicação específica, cabe se pensar a relação que estabelece na contigüidade com seu exterior em termos da continuidade ou ruptura do movimento circundante. Neste período de radicalização da dinâmica da experiência instituída no nascimento da cidade moderna, a leitura, enquanto prática que se performa temporalmente, organiza, por si só, ritmos desta experiência, distendendo ou comprimindo a duração pela instauração de um escoar próprio do tempo.

Por esta justaposição, em que a leitura demarca com fronteiras permeáveis seu território na experiência, ameaça-se a irredutibilidade dos tipos de leitores na multiplicidade constitutiva dos sujeitos. Compreendemos que a revista Piauí, neste quadro, não apenas suscita tais questionamentos como, também, ao travar constante diálogo com diferentes situações de leitura na constituição de uma própria, se oferece como objeto privilegiado para se pensar este sujeitoleitor contemporâneo e seu trânsito pelas diversas instâncias de seu entorno tipográfico.

\section{Dispositivos, tipos e fronteiras piauienses}

Ana Gruszynski ${ }^{15}$ lembra que a articulação de dispositivos tipográficos na constituição da materialidade do texto se dá em constante relação com os leitores na efetuação da leitura. A materialidade sensível dos meios orienta este processo efetuado pelos sujeitos, que se situam numa interação com o texto num jogo que mobiliza expectativas
14-SANTAELLA, 2004, p. 19-20. 15- GRUSZYNSKI, 2004. 
16 - CHARTIER, Roger; CAVALLO, Guglielmo. História da leitura no mundo ocidental. São Paulo: Ática, 1998. Apud GRUSZYNSKI, 2004.

17- AUMONT, 1993, p. 136. 18- Este tipo de invasão do texto pela imagem é prática comum nas mais diversas publicações, sobretudo em revistas. de um e de outro. Naturalmente, neste processo atravessam diversos outros fatores para além da materialidade física da publicação, como a narrativa textual ou a constituição temática envolvida. Porém, esta materialidade sensível constitui fator determinante no jogo de reconhecimentos, porta de entrada dos sujeitos que se dispõem inicialmente à leitura, que delineia também um tênue território de leitura, orientando posturas perceptivo-cognitivas dos leitores no decurso da experiência.

Enquanto conformadores da materialidade do texto, os dispositivos tipográficos são a condição de sua existência sensível aos leitores. Tomando a formulação de Chartier e Cavallo, "os autores escrevem textos que se tornam objetos escritos manejados de diferentes formas por leitores de carne e osso, cujas maneiras de ler variam com as épocas, os lugares e os ambientes"16. Situamos, portanto, os tipógrafos, diagramadores e designers nesta transição que vai do texto ao objeto, articulando as instâncias sensíveis da significação.

Porém, mais do que simples materialidade dos textos, os dispositivos tipográficos se constituem como articuladores da relação que se

leitor no processo de leitura. É neste sentido que os dispositivos tipográficos possuem participação significativa na construção da experiência de leitura, direcionando o olhar do leitor na démarche de efetuação do texto.

Buscamos, portanto, compreendercomo se articulam os dispositivos tipográficos de Piauí, que dão materialidade ao seu conteúdo, de modo a compreender a experiência de leitura construída a partir do jogo de expectativas com seus leitores e suas características de mobilidade e adaptabilidade apresentadas.

Como princípio fundamental que rege esta articulação, observa-se, ao longo de toda a revista, sobretudo no corpo dos textos, uma contínua preocupação com o equilíbrio funcional da composição de suas páginas e com os princípios tipográficos de conforto e legibilidade necessários à leitura de seus textos extensos (Fig. 7 e Fig. 8). Preocupação que se evidencia na escolha da tipografia, na extensão moderada das colunas, na uniformidade da mancha e relação equilibrada com as ilustrações - que em momento algum invadem o espaço do texto, deformando as colunas, fazendo-as incorporar as curvas da imagem ${ }^{18}$. Neste processo, os dispositivos tipográficos estabelece entre os textos e os sujeitos, de forma similar ao que Jacques Aumont, trabalhando o conceito de dispositivo, diz de sua função no movimento de transição entre o espaço do espectador e o espaço plástico da imagem ${ }^{17}$. Assim os dispositivos tipográficos trabalham tanto numa ordem interna dos textos, hierarquizando os conteúdos, quanto numa ordem externa, atuando na dimensão relacional que vincula o sujeito- se evidenciam enquanto articuladores de uma dimensão relacional da leitura, pois é assim que a publicação se oferece enquanto terreno hospitaleiro ao leitor que se dispôs à leitura da revista. Com sua austeridade sofisticada, chama-se à leitura sem, contudo, invadir o espaço do leitor. É ele que é convidado a se enveredar pelo território de Piauí, a percorrer o caminho que ela abre ao campo esquecido e pouco arado da leitura silenciosa, com 
um projeto gráfico que abafa os berros e apaga as luzes do entorno, constituindo, na própria página, o retiro deste leitor.

Esta característica, contudo, ainda que fundamental, deve ser inserida no conjunto da publicação, em que se performam estratégias outras de conformação tipográfica responsáveis pela relação da revista com ambiente tipográfico contemporâneo, garantindo sua inserção, ainda que distintiva, na

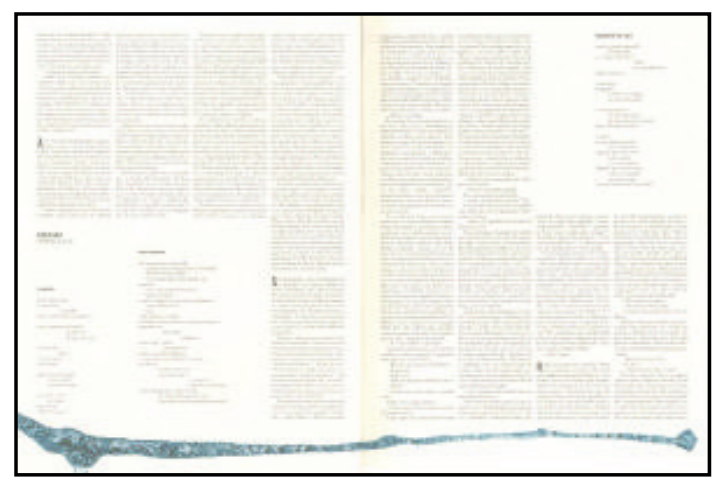

Fig. 7 - Piauí, ano 1, número 7, abr 2007. p. 46-47.

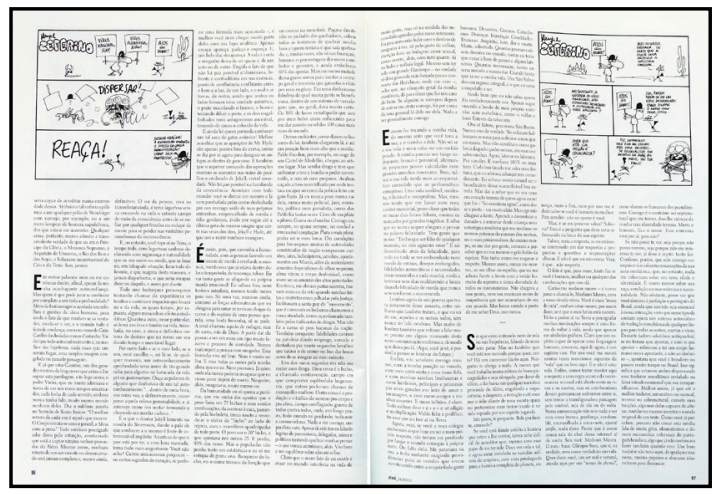

Fig. 8 - Piauí, ano 8, número 85, out 2013. p. 97-97.

multiplicidade de leituras do sujeitoleitor.

Assim, constatamos que o design tipográfico de Piauí transita no tempo, podendo retroceder a um passado histórico da imprensa, ao oferecer plenas páginas de texto sem ilustrações; ou avançar, dispondo grandes ilustrações sangradas com textos mínimos e destacados textos em layout para a varredura do olhar do leitor, ao modo de leitura de telas com o cursor de rolagem verticalizado ou responsivas ao toque e ao deslize do dedo ${ }^{19}$. Dispensa-se o mouse, aplicam-se os olhos na página.

Vale ressaltar alguns precedentes desta visualidade centrada no texto, buscadas na primeira metade do século XIX. Em formato similar ao de Piauíe, às vezes, com o mesmo número de (quatro) colunas, aquelas antigas "folhas" recorriam a uma ou duas fontes tipográficas, oferecendo suas matérias com mínimos destaques em pequenos títulos e sem destaques de ilustrações, cuja ausência ou pouquíssima freqüência se devem às dificuldades técnicas de reproduções àquela época. $\mathrm{O}$ que se via nos primórdios da imprensa, então, é parcialmente recuperado e oferecido por Piauí a seus leitores propensos a uma leitura silenciosa, ou, no máximo, murmurante, sussurrante. Consumidores modernos do impresso parecem experienciar e atualizar processos vividos há mais de 150 anos, quando se principiava a ultrapassar os limites do gabinete de leitura da era préindustrial para lançar-se ao nascente fluxo hiperestimulante da modernidade. Basta lembrar-se da profusão tipográfica ocorrida ao longo do século XIX, devido ao uso da litografia em embalagens e cartazes

A essa massa tipográfica serifada, porém sofisticada, que percorre linearmente as quatro colunas do grid, remetendo à diagramação das publicações do século XIX, contrapõese um jogo, nas vinhetas e no logotipo da publicação (Fig. 5 e Fig. 6), bem mais próximo da cultura tipográfica do século XXI. A fonte utilizada sugere um desenho tipográfico voltado para a tela de raios
18- $A$ este respeito, nos referimos, sobretudo, às chamadas da capa (Fig. $1 \mathrm{e}$

Fig. 2), organizadas uniformemente em estreitas colunas alinhas em bandeira. 19- A este respeito, nos referimos, sobretudo, às chamadas da capa (Fig. 1 e Fig. 2), organizadas uniformemente em estreitas colunas alinhas em bandeira. 
catódicos, com suas particularidades de exibição da imagem - desmembramento em linhas de varredura e em pontos luminosos - e certamente constrói uma aparência contemporânea à publicação. O underscore - elemento tipográfico relacionado diretamente à web, utilizado na grafia de endereços eletrônicos na supressão de espaços em branco - na edição 7 separa o nome da revista da data da edição, e na edição 85 separa o número da edição do nome da revista. Outros sinais tipográficos evidentes da contemporaneidade em Piauí são o uso da caixa baixa, com inicial minúscula, no nome da publicação, e a indicação do ano de 2007 apenas pelos dois últimos dígitos, uma prática recorrente na informática,

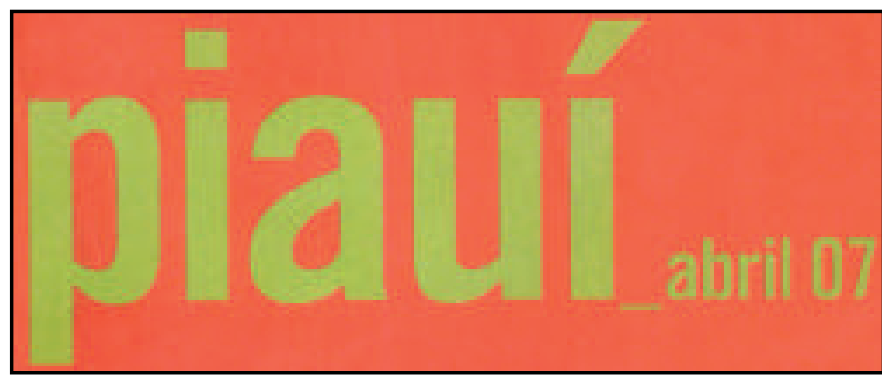

Fig. 9 - Piauí, ano 1, número 7, abr 2007. Capa (detalhe).

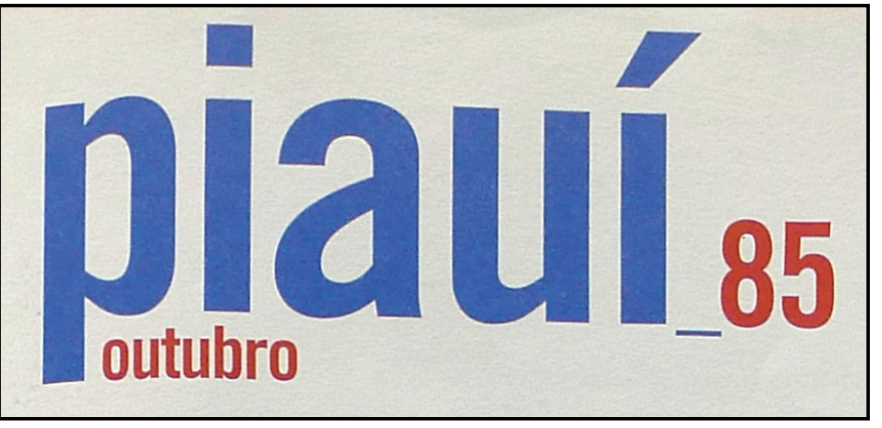

Fig. 10 - Piauí, ano 7, número 85, out 2013. Capa (detalhe).

que institucionalizou esta representação como forma de economia de espaço desde os primórdios da computação.

$\mathrm{Na}$ constituição desta identidade

20- Piauí, ano 1, número 7 , 20-Piauí, ano 1, número 7, abr 2007. relativa da experiência móvel de leitura inserindo-se nesta própria realidade, insinuando um perfil de contemplação num espaço - o dos periódicos - de que se espera a continuidade, na página, do fluxo movente do entorno.

\section{Territórios estrangeiros}

Em meio à unidade gráfica da revista, nos deparamos com a matéria "Phaic Tan: um assalto aos sentidos"20 (Fig. 11), que num primeiro momento destoa visualmente da publicação. Todas nossas observações anteriores parecem ser contraditas por esta excepcionalidade: enorme quantidade de fotografias, não tão belas; mapas; infográficos; boxes; subtítulos; e inúmeros destaques em negrito no corpo do texto.

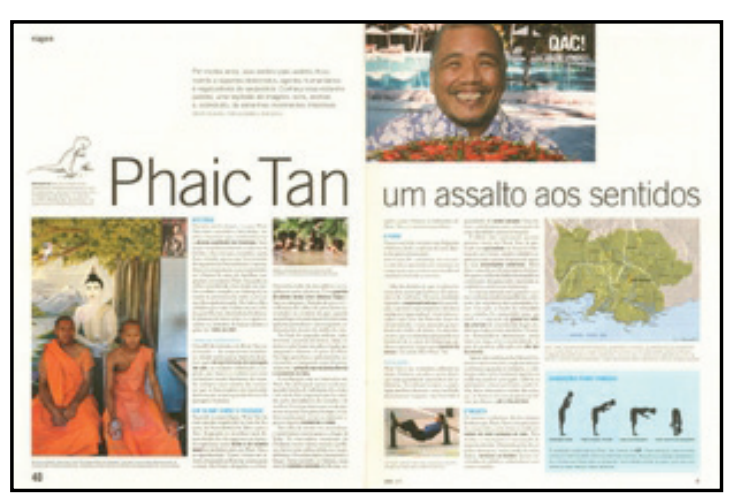

Fig. 11 - Piauí, ano 1, número 7, abr 2007. p. 40-41.

Porém, o leitor reconhece logo o tom humorístico do texto, um pastiche de matérias turísticas que se refere a um país fictício do sudeste asiático. Desfazse o estranhamento. Phaic Tan, país descrito como "explosão de imagens, sons, aromas e, sobretudo, de estranhos movimentos intestinais" ${ }^{21}$, insinua-se, em Piauí, como o estrangeiro exótico e aversivo. Graficamente, o hiperestímulo e a variedade tipográfica aí se inserem num turbilhão caótico, em que estratégias de ordenação e hierarquização - como os 
destaques em negrito - se transfiguram em anarquia textual. Desfaz-se a experiência de leitura serena.

Um assalto aos sentidos. Com efeito. Em oposição à elegante economia de estímulos do restante da publicação, "Phaic Tan" salta da página a nossos olhos num ato de violência, chama nossa atenção como um convidado indesejado a invadir nossa intimidade. A matéria reforça graficamente a distinção da revista frente à tendência predominante do ambiente tipográfico e periodístico. Conferindo humor e estranhamento a um lugar comum dos impressos, Piauí desconstrói seus procedimentos, neles ressaltando um certo tom de ridículo. comemorativa de número 13 , com o primeiro "The Piauí Herald" reserva páginas eventuais para esta família de periódicos intrusos - que também inclui: "The Maranhão Herald" (ano 4, número 37), “The Bulgária Herald” (ano 5, número 51), "The Cafe-Soçaite Herald" (ano 6, número 61) e, posteriormente, "The Lavigne Herald" (ano 7, número 86). Em referência direta ao escândalo de espionagem estadunidense então recém deflagrado pelo analista de sistemas Edward Snowden, o "NSA Herald" traz às páginas da revista cômicos "boletins confidenciais" da agência de segurança a respeito do Brasil, em estética "detetivesca" retrô - com notas datilografadas,

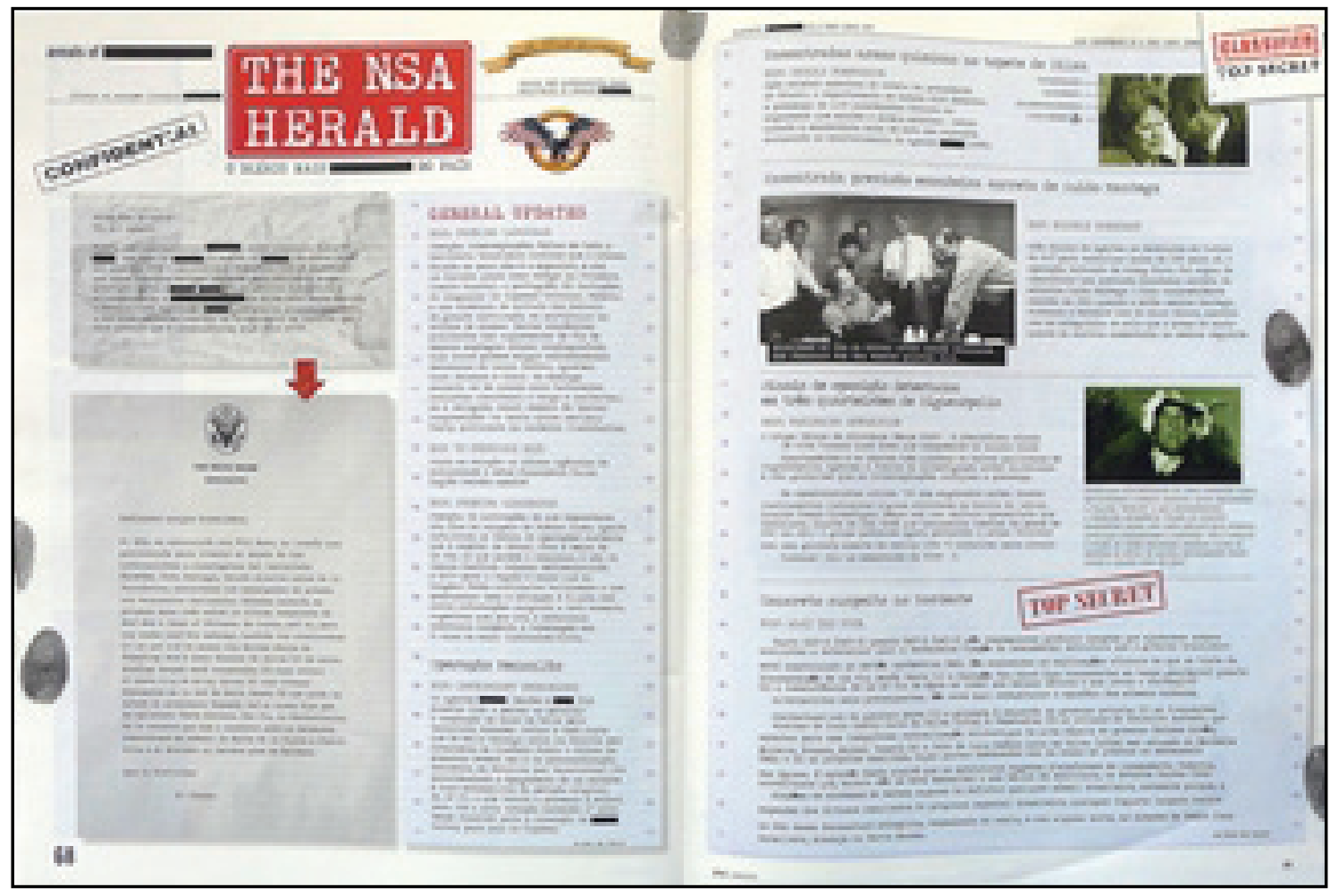

Fig. 12 - Piauí, ano 8, número 85, abr 2013. p. 68-69.

Na edição de número 85, mais uma vez encontramos este contraponto, agora na figura de "The NSA Herald" (Fig. 12) 22 . Uma brincadeira, a este momento, já usual da publicação, que desde a edição carimbos e tarjas de censura - que parece remeter, mais do que aos documentos em si, ao tratamento geralmente adotado pela grande imprensa ao divulgá-los. Um jornalismo investigativo às avessas.
22- Piauí, ano 7 número 85, p. 68 - 
Com "Phaic Tan" e "The NSA Herald", na apresentação de um outro território, Piauí faz o reforço de sua própria identidade em outra experiência de leitura diametralmente oposta à sua. Demarcando um lado de fora, ela reforça os contornos de suas próprias fronteiras, mas não deixa de avizinhar o que lhe é estranho.

\section{O deslocamento das fronteiras}

Não constitui objetivo deste artigo precisar uma categorização da revista Piauí frente a uma tipologia das práticas de leitura. Pelo contrário, nosvalemos da análiseda publicação como um impulso para a problematização do esforço classificatório de Santaella, na medida em que esta revista se situa num território em que se entrecruzam as mais diversas práticas de leitura, empreendidas por aquele a quem viemos nos referindo como múltiplo sujeitoleitor contemporâneo.

No solapamento de tempos históricos distintos, dos jornais do século XIXà web, Piauí articula a constituição de uma experiência de leitura distinta direcionada a um sujeitoleitor híbrido, habituado ao trânsito entre múltiplas realidades tipográficas. Buscando na profundidade da página o escape a uma experiência de leitura que lhe apraz, este sujeito-leitor encontra, aí, uma publicação que não se destaca de seu próprio tempo, mas que, sem se render a uma utopia árcade, sugere a inserção, nesta mesma realidade atual, de uma intermitência transitória a seu ritmo acelerado. Pelas referidas características de sua constituição gráfica, Piauí insinua, no seio de uma realidade movente, que avizinha uma virtualidade imersiva, um refúgio que se constitui pela própria experiência de leitura, alheia ao recolhimento físico do sujeitoleitor. É neste sentido, portanto, que achamos pertinente sugerir esta constituição de fronteiras fugazes de um território de leitura próprio à revista Piauí.

23-ECO, 2003.

24-BAR-

THES. 2006, p. 18. reflexões sobre o lugar do impresso em meio às múltiplas leituras empreendidas pelos sujeitos-leitores contemporâneos. Umberto $\mathrm{Eco}^{23}$, refletindo sobre esta questão, aponta para um certo deslocamento das práticas de leitura frente ao surgimento de novos suportes. Parte-se da noção de que a Internet, enquanto o novo suporte da contemporaneidade, não viria a atestar a obsolescência do impresso, mas, sim, mobilizar um reajuste das práticas de leitura, na medida em que se mostra mais adequada para algumas - como a leitura de consulta -, mas não a outras - como a leitura de um romance. Parece-nos instigante relacionar este deslocamento efetuado por Piauí a experiências de leitura alheias às dos periódicos tradicionais (e do próprio ambiente tipográfico circundante) enquanto uma insinuação deste movimento apontado por Eco. Afinal, para além da constatação de um sucesso deste empreendimento editorial, parece-nos claro, em nossa investigação, que Piauí ocupa um território novo no mercado editorial brasileiro, proporcionando uma experiência de leitura singular no conjunto do ambiente tipográfico contemporâneo. Experiência esta caracterizada pela distensão temporal e pela serenidade com que acolhe o leitor que parecia se encontrar perdido até o aparecimento de Piauí em outubro de 2006.

Se compreendermos a apreciação da leitura enquanto localizada, retomando Barthes, nas "esfoladuras que imponho ao belo envoltório" 24 , a corporeidade sensível do texto assume lugar central na compreensão do prazer da experiência de leitura e, inclusive, da manutenção do impresso enquanto suporte privilegiado a determinado tipo de leitura. Não há como afirmar que este prazer seja próprio de tal ou qual suporte, mas, certamente, na medida em que ele se realiza na experiência da leitura e na interação sensível do leitor com a corporeidade do texto, a natureza do prazer proporcionado por cada meio guarda, cada qual, sua particularidade. 


\section{Referências bibliográficas}

AUMONT, Jacques. A imagem. Campinas: Papirus, 1993.

BARTHES, Roland. O espírito da letra. In: BARTHES, Roland. O óbvio e o obtuso: ensaios críticos III. Rio de Janeiro: Nova Fronteira, 1990. pp. 93-96.

O prazer do texto. São Paulo: Perspectiva, 2006.

BENJAMIN, Walter. Revisor de livros juramentado. In: CAMPOS, Augusto de;

CAMPOS, Haroldo de; PIGNATARI, Décio. Mallarmé. São Paulo: Perspectiva, 2006. pp. 205-206.

BRINGHURST, Robert. Elementos do estilo tipográfico: versão 3.0. São Paulo: Cosac \& Naify, 2005.

CERTEAU, Michel de. A invenção do cotidiano: 1. artes de fazer. Petrópolis: Vozes, 1994.

CRARY, Jonathan. A visão que se desprende: Manet e o observador atento do fim do século XIX. In: CHARNEY, Leo; SCHWARTZ, Vanessa R. (Org.). O cinema e a invenção da vida moderna. São Paulo: Cosac \& Naify, 2004. pp. 67-94.

CUNHA, Tito Cardoso e. Silêncio e comunicação: ensaio sobre uma retórica do nãodito. Lisboa: Livros Horizonte, 2005.

DONDIS, Donis A. Sintaxe da linguagem visual. São Paulo: Martins Fontes, 1997.

ECO, Umberto. Muito além da Internet. Folha de S. Paulo, São Paulo, 14 dez 2003. Caderno Mais!, pp. 4-11.

GOMES FILHO, João. Ergonomia do objeto: sistema técnico de leitura ergonômica. São

Paulo: Escrituras Ed., 2003.

GRUSZYNSKI, Ana. Retórica tipográfica e leitura. Trabalho apresentado no NP 04 Produção Editorial no XXVII Congresso Brasileiro de Ciências da Comunicação, IV Encontro dos Núcleos de Pesquisa da Intercom, Porto Alegre, RS, 2004. Disponível em:

$<$ http://reposcom.portcom.intercom.org.br/bitstream/1904/17524/1/R0486-1.pdf>. Acessado em 21 maio 2007. 
MASSIN. La lettre et l'image. Paris: allimard,1973.

La mise en pages. Paris: Hoëbeke, 1991.

MOUILLAUD, Maurice. Da forma ao sentido. In: ; PORTO, Sérgio Dayrell (Org.). O

jornal: da forma ao sentido. Brasília: Paralelo 15, 1997. pp. 29-35.

OLIVEIRA, Ana Cláudia Mei. A leitura do jornal como experiência sensível. Revista da Anpoll, Campinas, n. 21, 2006. pp. 165-200.

RICHAUDEAU, François; BINISTI, Olivier. Manuel de typographie et de mise en page: $d u$ papier à l'écran. Paris: Retz, 2005.

SANTAELLA, Lúcia. Os três tipos de leitor: o contemplativo, o movente e o imersivo. In: SANTAELLA, Lúcia. Navegar o ciberespaço: o perfil cognitivo do leitor imersivo. São Paulo: Paulus, 2004.

SPENCER, Herbert. The visible word. New York: Visual Communication Books, 1969.

SINGER, Ben. Modernidade, hiperestímulo e o início do sensacionalismo popular. In: CHARNEY, Leo; SCHWARTZ, Vanessa R. (Org.). O cinema e a invenção da vida moderna. São Paulo: Cosac \& Naify, 2004. pp. 95-123.

Este artigo e todo o conteúdo da Estudos em Jornalismo e Mídia estão

disponíveis em https://periodicos.ufsc.br/index.php/jornalismo

Estudos em Jornalismo e Mídia está sob a Licença Creative Commons 2.5 